\section{WORKFORCE DEVELOPMENT \& EDUCATION \\ Analysis of TDS concentration in relation to oil and gas produced water disposal ponds in Kern County, California}

Valerie Petela1, Charuleka Varadharajan², Preston Jordan ${ }^{2} \quad{ }_{2}^{1}$ Geology Department, California State University, Sacramento Lawrence Berkeley National Laboratory, Berkeley, CA

\section{ntroduction and Background}

California ranked third in the nation for oil and gas production in 2016 (EIA, 2017). Groundwater

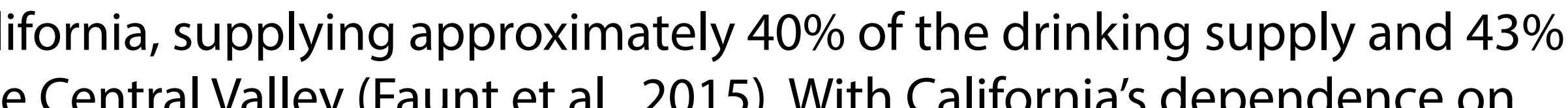
soundwater, it is crucial that water practices be assessed to determine impacts on groundwater

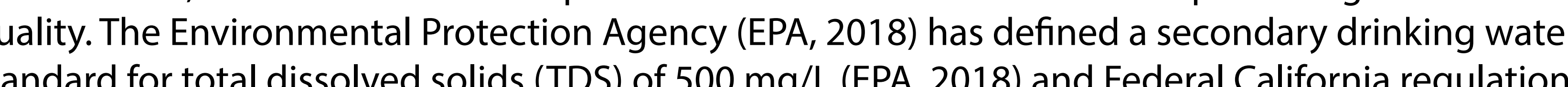
generally protect aquifers with less than 10,000 $\mathrm{mg} / \mathrm{L}$ TDS as underground sources of drinking Mast oil and gas production (72\% in 2016) occurs in Kern County, located in the San Joaquin
Basin (DOGGR, 2016). On average, for every barrel of oil produced there are 17 barrels of water extracted with it (DOGGR, 2016), known as produced water. Produced water from conventional ol 作

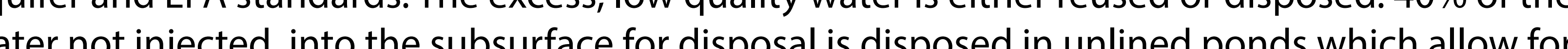
percolation and evaporation (DOGGR, 2017). Unlined ponds are a direct pathway for contamination cthe shallow aquifer system. High TDS water with unknown chenical composition or hazards

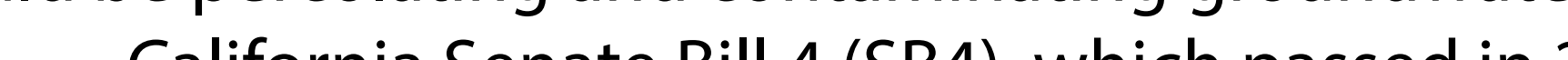

assessment of hydraulic fracturing and well stimulation practices in California. It recommended produced water be enalyzed for hazardous constituents and if they are present or not proven to be ion (CCST 2015). Several other U.S. states have disallowed the use of unlined ponds due to cases of water contamination.

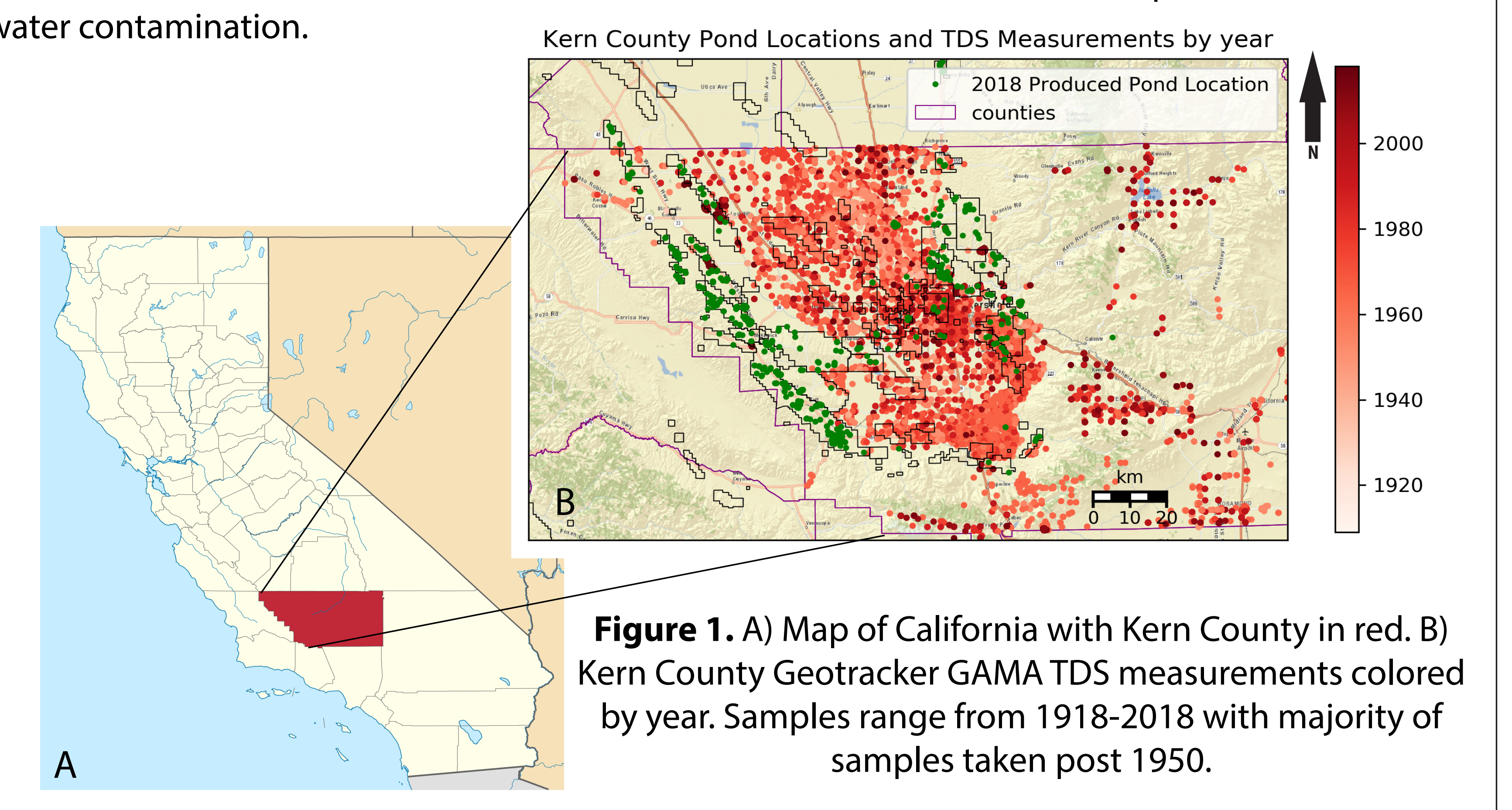

\section{Objective}

The objective of this research study was to determine if groundwater quality near ponds exhibits
higher or increasing TDS concentrations due to migration of high salinity produced water. This 作 ruleka/LBNL-CA-ProdWaterDisposal). It is important to note that it may be difficult to identify trends on the western side of the valley where groundwater has a naturally higher TDS concentration.

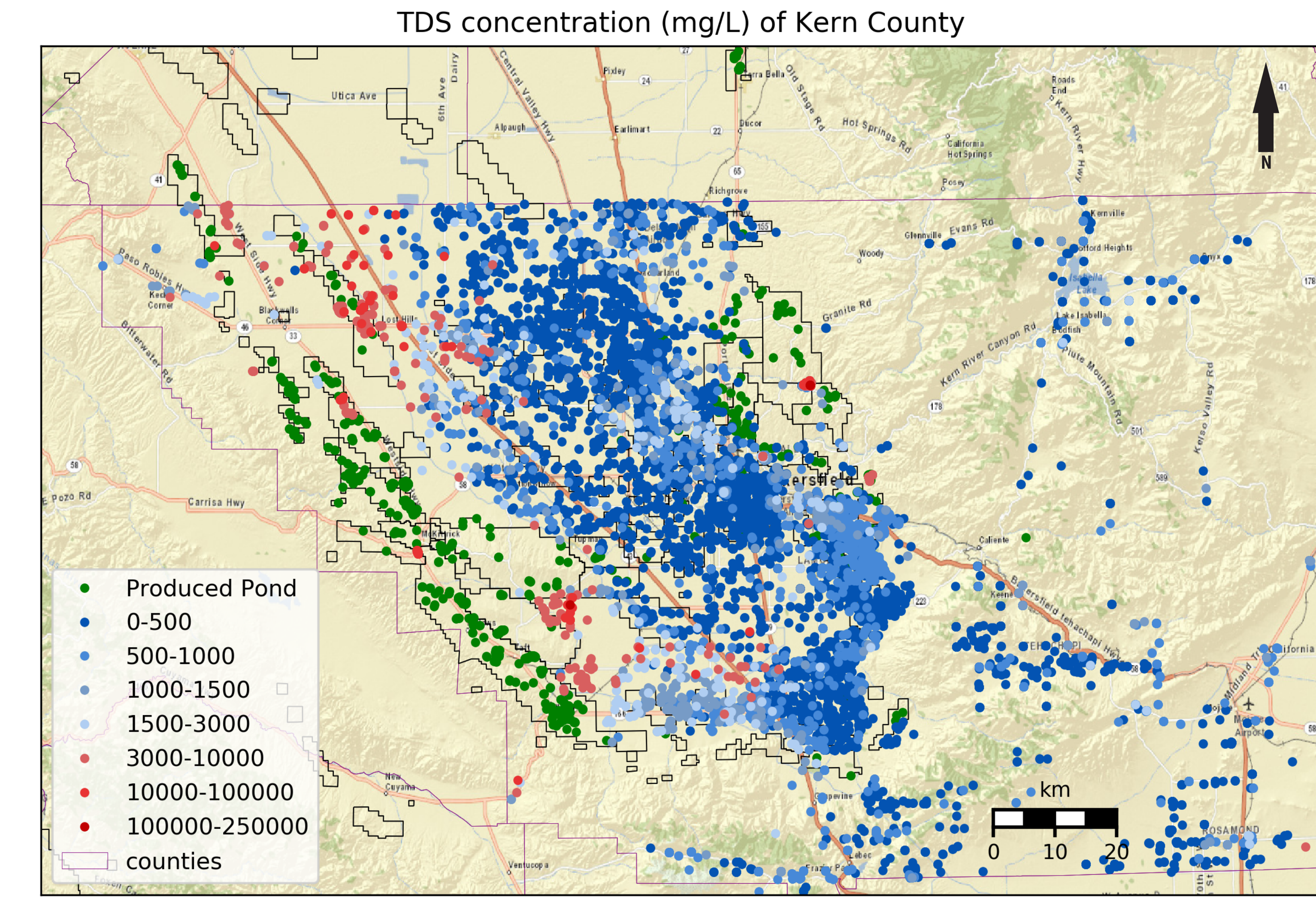

Figure 2. TDS measurements of Kern County colored by concentration. High TDS
measurements are concentrated in the western portion of study area where local geology produces higher salinity water and more produced ponds exist.
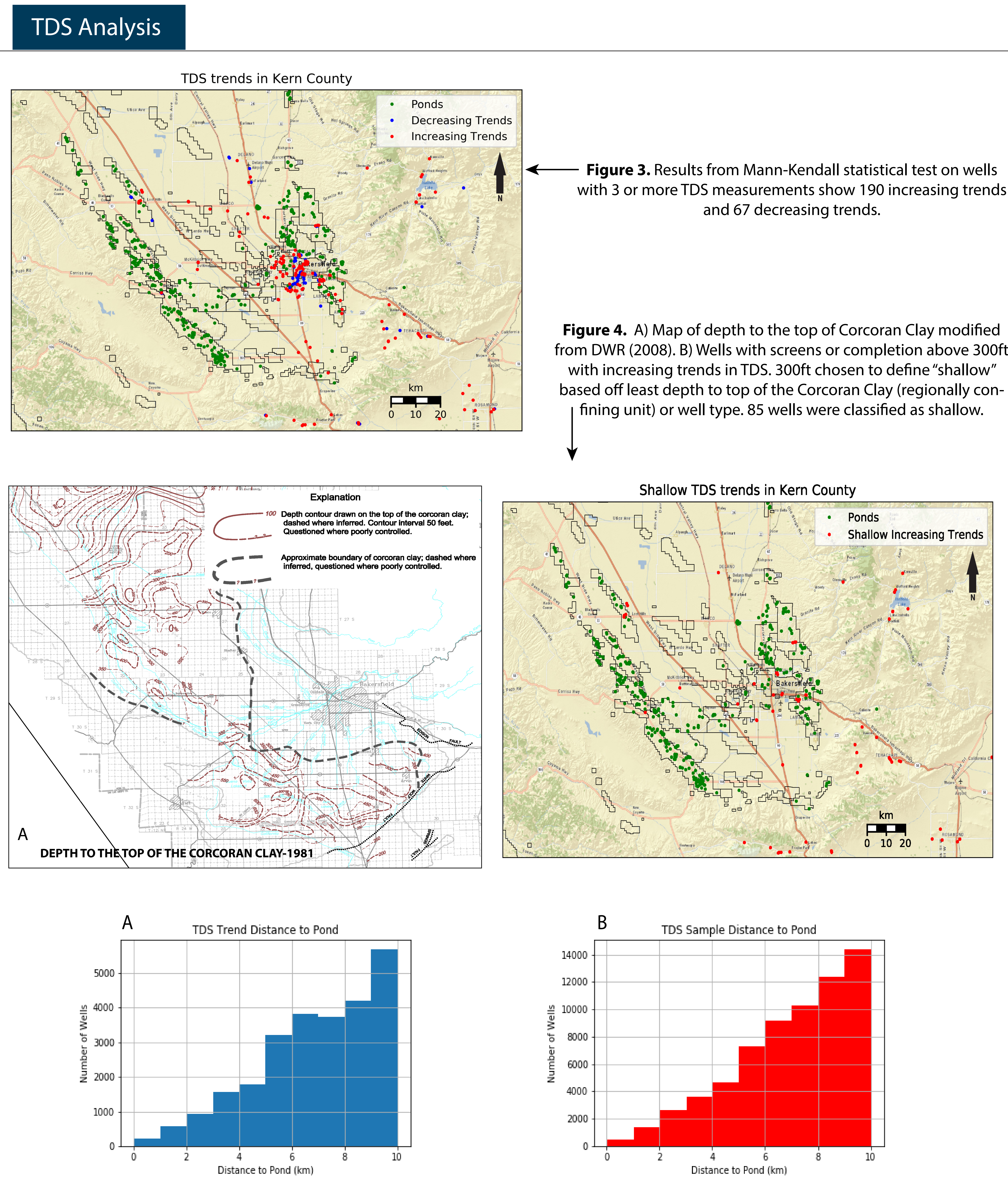

Figure 5. A) Histogram of each well's distance to each pond within $10 \mathrm{~km}$. B) Histogram of wells with increasing TDS trends and distance to each pond w
positive correlation of number of wells to distance.
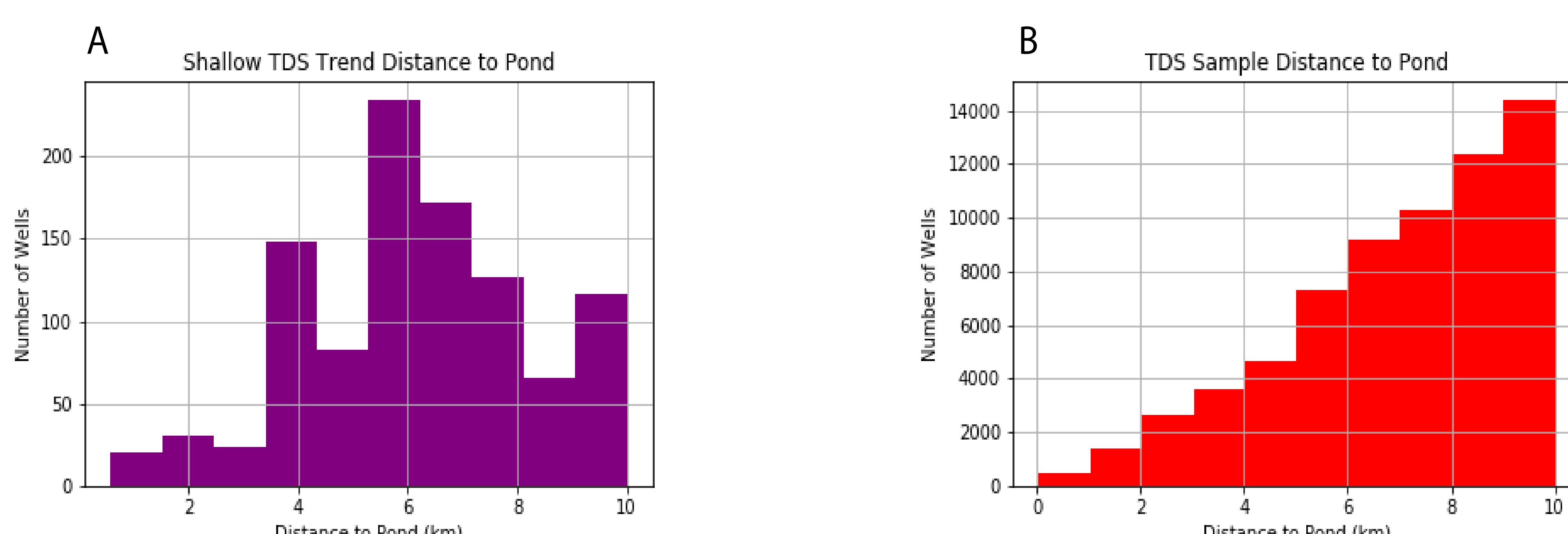

Figre 6. A) Histogan ofwelsw

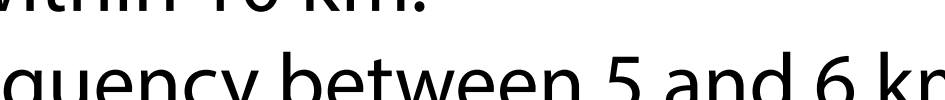

\section{Chemical Analysis}

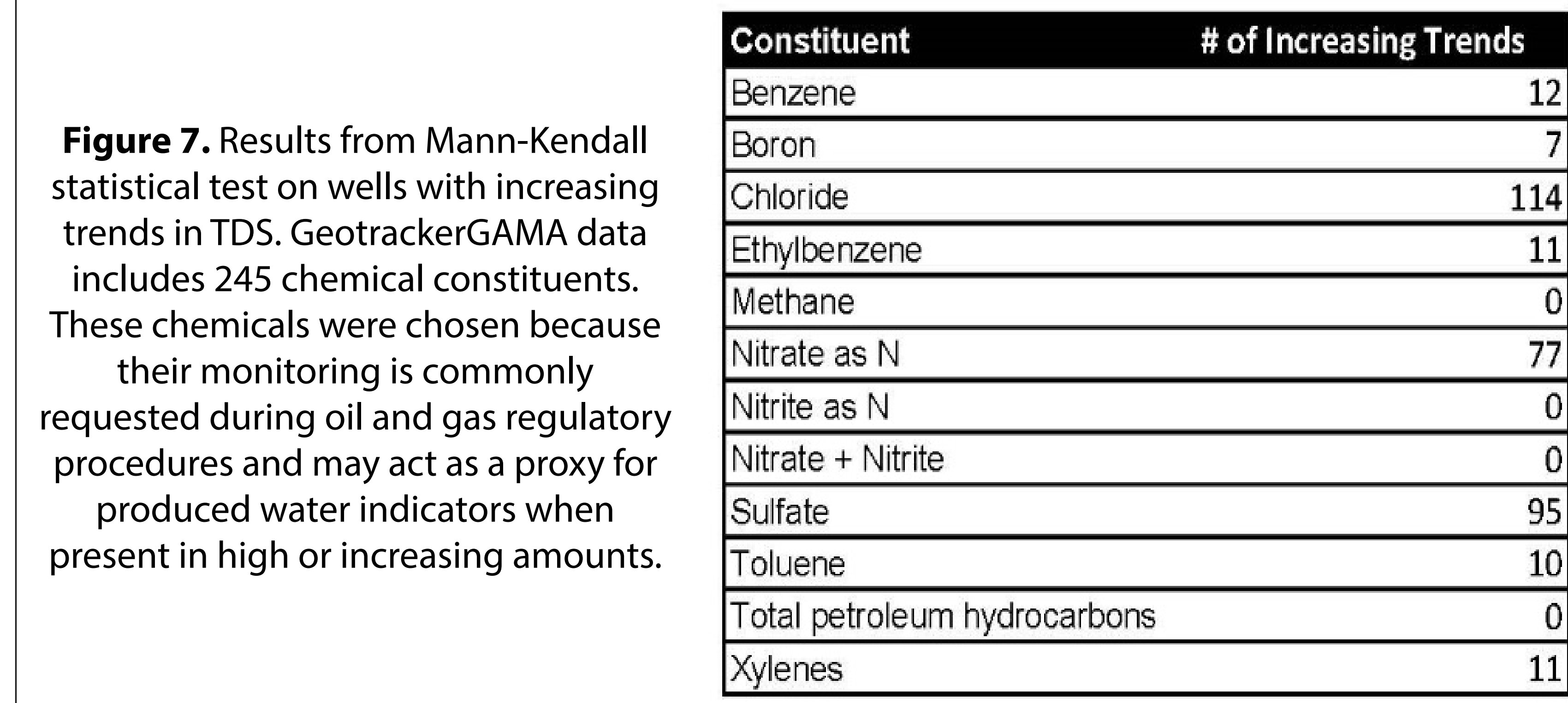

\section{Conclusions}

Shallow wells are more likely to be influenced by produced water

- Of 6,053 wells with TDS observations, 1,956 wells had three or more measurements

-More continuous time-series data are required to further test hypothesis
-Mann-Kendall trend analysis showed 190 wells with increasing trends

and 67 wells with decreasing trends

85 wells with increasing trends in TDS were classified as shallow
$46 \%$ percent of wells with hthree or more $D$ mS measurements and $42 \%$ percent of shallow wis
of a disposal pond

\section{Future Work}

- Determine further produced water indicators

- Refine proxy chemical list and rerun analysis
Incorporate DOGGR or operator provided geochemical water analysis - Calculate percolation potential of ponds to determine spatial extent of produced

Crear movement

\section{References}

- CST, 2015, Lawrence Berkeley National Laboratory.An Independent Scientific Assessment of Well Stimulation in California, vol.2 2 .
-EA (U.S. Energy Information Administration), 2017, Petroleum \& Other Liquids-Crude Oi Production: https://www.eia.gov/dnav//pet/pet__crd_crpdn_adc___ Faunt, C.C.,., Sneed, M., Traum, J., Brandt, J.T., 2015, Water availability and land subsidence in the Central Valley, California,

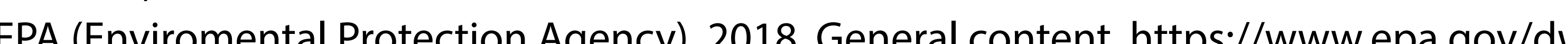
standardsregulations/secondary-drinking-water-standards-
-DOGGR (Division of Oil, Gas, and Geothermal Resources), 2016, Well Count and Production of oil, Gas, and Water by County-2016 ftpp://ftp.consrv.ca.gov//pub/oil/annual_re - CSST (California Council on Science and Technology), 2014, Lawrence Berkeley National Laboratory, and Pacific Institute, 2014, Advanced Well Stimulation Technologies in Chttr//ccstus/publentions/2014/2014wstpdf Resources Quarterly Reports: http://www.conservation.ca.gov/dog//SB\%201281/Pages/ BB_1281DataAndReports.aspx

- Department of Water Resources 2008, Depth to the top of Corcoran Clay-1981, clay_map_1981/depth_to_the_top_of_corcoran_lay-1981.pd 